\section{MAXILLARY PREMOLAR TEETH: ROOT AND CANAL STEREOSCOPY}

\section{Aisha Sadaf $^{1,2}$, Zilli Huma $^{2 凶}$, Sumaira Javed ${ }^{2,3}$, Aasim Masood'}

\begin{abstract}
OBJECTIVE: To identify and compare the variations in the root and canal morphology of maxillary first and second premolars in the local population.

METHODS: Maxillary premolars $(n=210)$ were collected from local population from six hospitals and clinics of two cities i.e. Peshawar and Kohat, Pakistan. The demographics collected from the patients included linguistic ethnicity and gender. External morphological parameters; length, root form, mesial surface depression, were observed by the naked eye. These were then observed under stereomicroscope to identify the internal root morphology including canal form, lateral canals, and canal isthmi.
\end{abstract}

RESULTS: Common root form of first premolars was two rooted $(70 \%)$ while second premolars were single rooted $(81 \%)$. Mesial surface depression was more common in first premolars $(76 \%)$ than second premolars $(36 \%)$ $\mathrm{p}<0.00 \mathrm{I}$. In first premolars common canal configuration was Type IV $(62 \%)$ and type II (9.5\%) while in second premolars type I (20\%), II (35\%), IV (I I.4\%) and type $\mathrm{VI}(24.8 \%)$ configuration were commonly found. Lateral canals and canal isthmi were a lesser common finding in both types of teeth.

CONCLUSION: Canal configuration of first premolars was most commonly type IV while that of second premolar was type I, II, VI and IV in our population. This indicates that second premolar has more diversity in canal configuration.

KEY WORDS: Maxillary Premolar (MeSH); Root Canal (MeSH); Clearing technique (Non-MeSH); Peshawar (Non-MeSH); Kohat (Non-MeSH); Pakistan (MeSH).

THIS ARTICLE MAY BE CITED AS: Sadaf A, Huma Z, Javed S, Masood A. Maxillary premolar teeth: root and canal stereoscopy. Khyber Med Univ J 2019; I (4):240-7. DOI: I0.35845/kmuj.20I9.19337

\section{INTRODUCTION}

E ndodontically maxillary premolars are difficult to treat because of variability in their morphology. The various factors including number of roots, canal configuration, the direction and longitudinal depressions of the roots, and various pulp cavity configuration all play a key role in treatment outcomes of dental procedures on these teeth. ${ }^{1,2}$ These procedures range from apipectomy, root canal treatment on internal structure and placement of prosthodontics appliances and aesthetics on external morphology of pre-molars.
Studies have identified certain external as well as internal morphological features of the human teeth. These features as identified by Vertucci and later by Sert have helped us differentiate between the anterior (incisors and canine) and posterior (premolars and molars) sets of teeth. Further, some of these characteristics have been identified as unique for the various populations of the world in terms of ethnicity, age and gender. ${ }^{5}$ For example, North American, Far Eastern and Turkish populations have identified significant racial variations in root and canal anatomy of maxillary pre molars. ${ }^{6}$ The techniques used to identify the root canal morphology vary from radiology
I. Khyber Medical University Institute of Dental Sciences (KMU-IDS), Kohat, Pakistan.

2. Khyber Medical University Institute of Basic Medical Sciences KMU-IBMS, Peshawar, Pakistan

Email『: surghuma73@gmail.com Contact \#: +92-320-9894379

3. Ayub Medical College, Abbottabad, Pakistan.

$\begin{array}{ll}\text { Date Submitted: } & \text { May 16,2019 } \\ \text { Date Revised: } & \text { October 22, 2019 } \\ \text { Date Accepted: } & \text { November 12, 2019 }\end{array}$

to in vitro techniques. Demineralization and staining is one such in-vitro technique that keeps instrumentation away from the root canal and prevents disruption of its natural anatomy. In addition this technique allows for a three dimensional picture of root canal by stereomicroscopy ${ }^{7}$ and further classification of root canal system. Though many of classifications are in vogue, a blend of Vertucci and additional classification given by Sert provides a much more holistic overview to the internal arrangement of these premolar canals.

The study was designed to classify premolar morphology using a standardized procedure for our population to help dental surgeons treating these patients in planning their procedures and reduce complications. The main aim was to compare first and second premolars canal morphology and its classification

\section{METHODS}

This was a multicenter laboratory based study on extracted human premolar teeth, done in Khyber Medical University, Institute of Basic Medical Sciences (KMU-IBMS), Peshawar and Institute of Dental Sciences (KMU-IDS), Kohat and Khyber Girls Medical College, Peshawar Pakistan, after approval from KMU ethical review board. Purposive sampling was done and sample size calculated (WHO sample size calculation, $5.2 \%$ proportion of bifid root in maxillary first pre molars, ${ }^{8} 95 \% \mathrm{Cl}$ ) as 210 maxillary premolars with equal numbers of first and second premolars. Only one tooth 
TABLE I: QUALITATIVE AND QUANTITATIVE VARIABLES OF PRE-MOLAR TEETH

\begin{tabular}{|c|c|c|c|}
\hline Anatomy & Data Type & Observation & Parameters \\
\hline \multirow{6}{*}{ External } & \multirow{3}{*}{ Quantitative } & \multirow{3}{*}{ Gross } & Tooth length \\
\hline & & & Absolute root length \\
\hline & & & Relative root length \\
\hline & \multirow{3}{*}{ Qualitative } & \multirow{2}{*}{ Gross } & Root form \\
\hline & & & Mesial depression \\
\hline & & Microscopic & Canal exit location \\
\hline \multirow{3}{*}{ Internal } & \multirow{3}{*}{ Qualitative } & \multirow{3}{*}{ Microscopic } & Canal Configuration \\
\hline & & & Lateral canals \\
\hline & & & Canal Isthmi \\
\hline
\end{tabular}

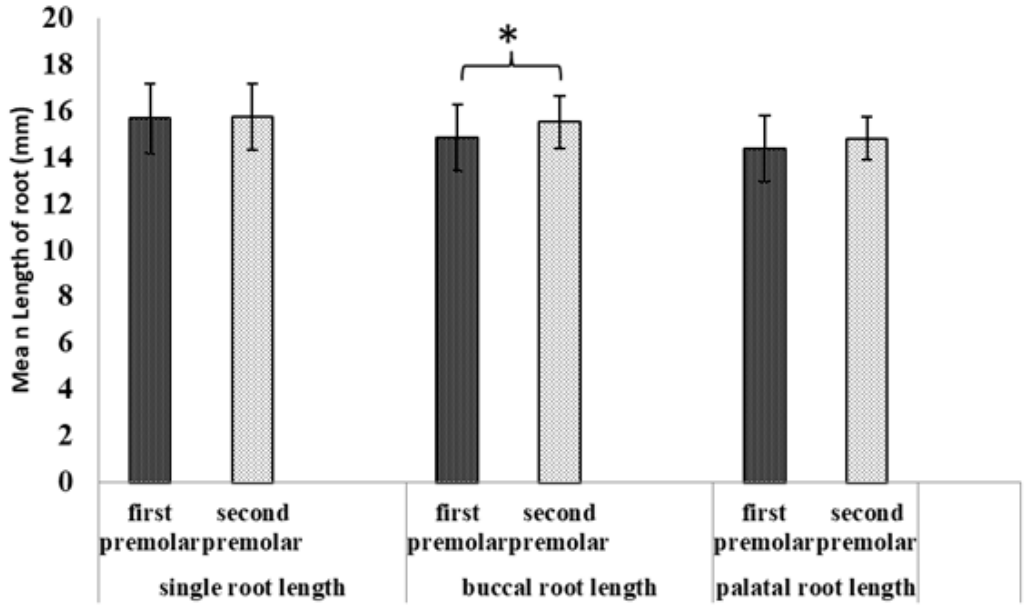

Figure I: Comparison of Ist and 2nd premolar root length $\left[{ }^{*} \mathrm{p}<0.05\right.$ (T- test) $=$ Significant difference in Buccal root length of the two groups]

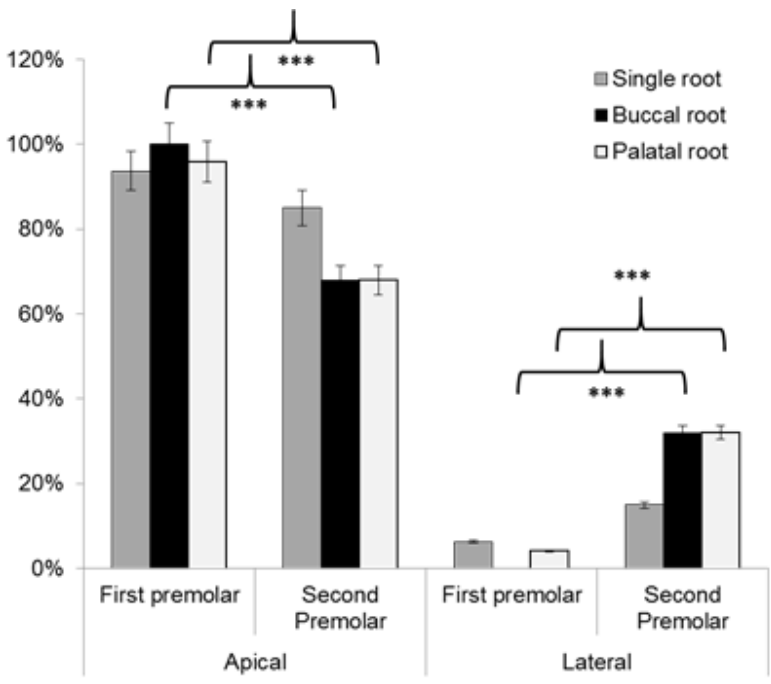

Figure 2: Comparison of canal exit location in premolars (*** $\mathrm{P}<0.00$ I, chi-square, $\mathrm{n}=210$ )

per adult patient was included in the study of ages between 20 and 60 years. Patients were probed for linguistic ethnicity and their gender was recorded on the collection sheets. Teeth with resorbed roots, fillings and peri-apical cysts were excluded from the study.

After collection teeth were washed, cleaned and stored in distilled water containing thymol crystals (antifungal agent). ${ }^{9}$ The external gross anatomical parameters of tooth/root length were recorded in the pre-processing phase using vernier caliper. Relative root length was then calculated as $\mathrm{RRL}=$ ARL/TL X 100 (RRL, relative root length; $A R L$, absolute root length; $T L=$ Tooth length). The number of roots as well as presence of mesial root depression was also noted. The teeth were then processed to observe internal anatomical parameters by fixing in 10\% formalin solution for 24 hours and shaken after every 8 hours. They were then treated with $5 \%$ solution of sodium hypochlorite (Dejung, Korea) for next 48 hours for removal of organic tissues. ${ }^{10}$ An access cavity was made with high speed rotary hand-piece (NSK-PANA max) and straight fissure stainless steel burr with moderate water spray during cutting. The pulp floor was removed. With small size endodontic file \# I5 and most obvious canals were cleaned of any loosely necrotic pulpal tissues present, if any. Teeth were then decalcified with $5 \%$ nitric acid" and then dehydrated with series of $70 \%, 80 \%, 90 \%$ and in $100 \%$ concentrated ethanol (AnalaR 100\%). ${ }^{12}$ Hematoxylin dye (Merck liquid) was injected with 23 gauge needle under high vacuumed compression suction negative pressure ensuring efficient flow of dye into the canals. Each tooth was dipped in liquid methyl salicylate for 72 hours to make it transparent.

Transparent teeth were examined under stereomicroscope, (Olympus Corporation Tokyo-Japan, Modal SZ6I); Photographs were taken by c a mera fixed on lens of stereomicroscope with resolution power, $2560 \times 920$ megapixels. Stereoscopic anatomy of the root canal configuration was classified according to Vertucci ${ }^{13}$ and Sert ${ }^{6}$ as well as lateral canals and canal isthmi were observed. The classification was validated by triangulation from two other expert researchers. Statistical analysis was done by using Statistical Package for Social Science (SPSS version 20.0) for both qualitative and quantitative 


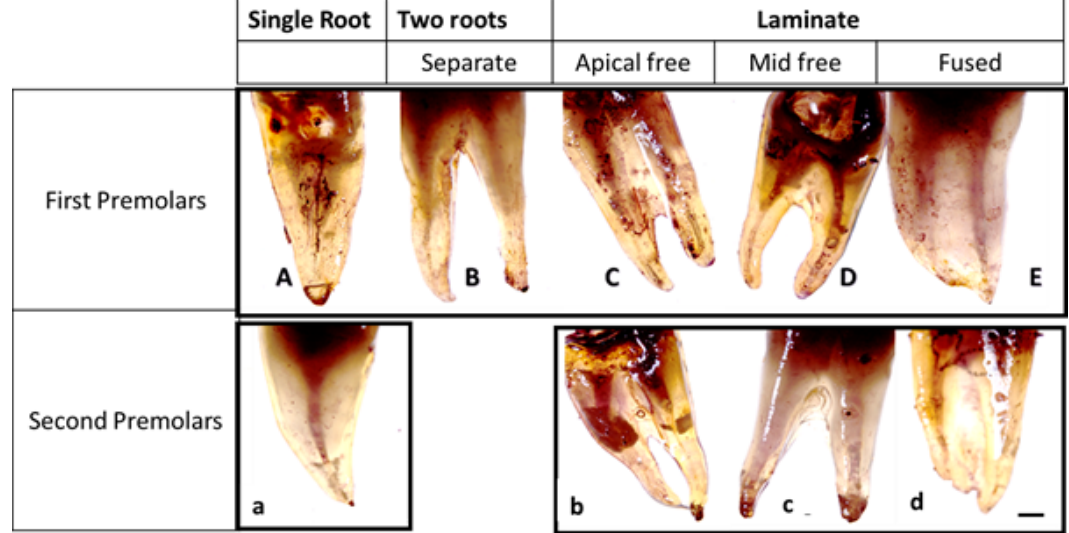

Figure 3: External root forms in First Premolars (A, B, C, D \& E) and Second Premolars (a, b, c \& d)

A,a: Single Root B: Two separate Roots, C, b:Laminated free at apexl/3 $D, c$ : Laminated free at middle $\mathrm{I} / 3 \mathrm{E}$, d: full fused bifid root $\quad$ Scale $=2 \mathrm{~mm}$

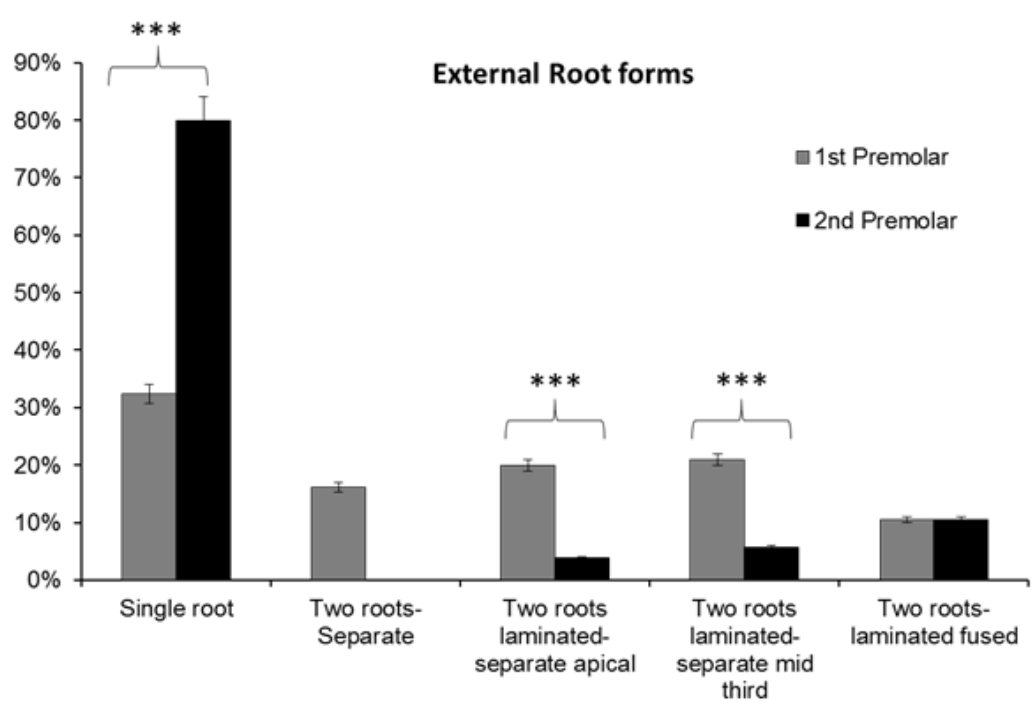

Figure 4: Comparison of external root forms in Premolars (**** $\mathrm{P}<0.00 \mathrm{I}$, Chi-Square test, $\mathrm{n}=210$ )

variables. Means \pm standard deviations were calculated for quantitative variables and frequencies and percentages were calculated for all qualitative variables (Table I). Inferential statistic was conducted in SPSS by applying three different tests depending upon type and number of variables.

I. Pearson chi-square test: Cross tabulation with Pearson chi-square test was applied for measure of association between two qualitative variables.

\section{RESULTS}

The outcome measures of this experimental study were root lengths, root forms and mesial depression on gross observation and canal configuration, exit and isthmi and lateral canals on microscopy.

The age of the patients ranged from 20 60 years with mean age of $40.33 \pm 11.48$ years and $41.29 \pm 10.39$ years for first and second premolar groups, respectively while ratio of males to females was equal. Linguistic ethnic groups Pashtun and Hindkun were in a ratio of 2:I.

The average tooth length ranged from $19-26 \mathrm{~mm}(21.39 \pm 1.31 \mathrm{~mm})$ and 17.5 $25 \mathrm{~mm}(21.13 \pm 1.39 \mathrm{~mm})$ for first and second premolar groups, respectively. The average root lengths ranged from $\sim 16$ to $\sim 15 \mathrm{~mm}$ with approximately $1 \mathrm{~mm}$ difference in lengths in both groups $(n=210)$. The differences in root length were only significant for buccal roots (Figure I). The relative root length was calculated for each group as a percentage of total tooth length ranging from $\sim 68 \%$ for palatal roots to $71 \%$ for buccal (double roots) and $\sim 74 \%$ for single roots. Each of these roots had either an apical or lateral canal exit with the majority of the single or double rooted teeth having an apical canal exit ( $~ 94 \%, 83 \%$, respectively). On the other hand only $4 \%$ and $32 \%$ teeth had lateral exit in first and second premolars respectively $(\mathrm{P}<.00 \mathrm{I}$, Chi-square test, Figure 2).

As illustrated in Figure 3 root forms were classified as: single rooted, two separate roots, laminated root free at apexl/3, laminated root free at middle $\mathrm{I} / 3$ and full fused bifid roots. In first pre-molars, five different types of external root forms were observed while four forms were observed in second premolars. The single root predominates in second premolar teeth by a far greater margin; $4: I$ as compared to $2: \mathrm{I}$ in first premolars $(\mathrm{P}<.00 \mathrm{I}$, chisquare test, Figure 4). However, there was no significant difference between males and females or ethnicity in distribution pattern of root forms.

Comparison between first and second premolars revealed highly significant 


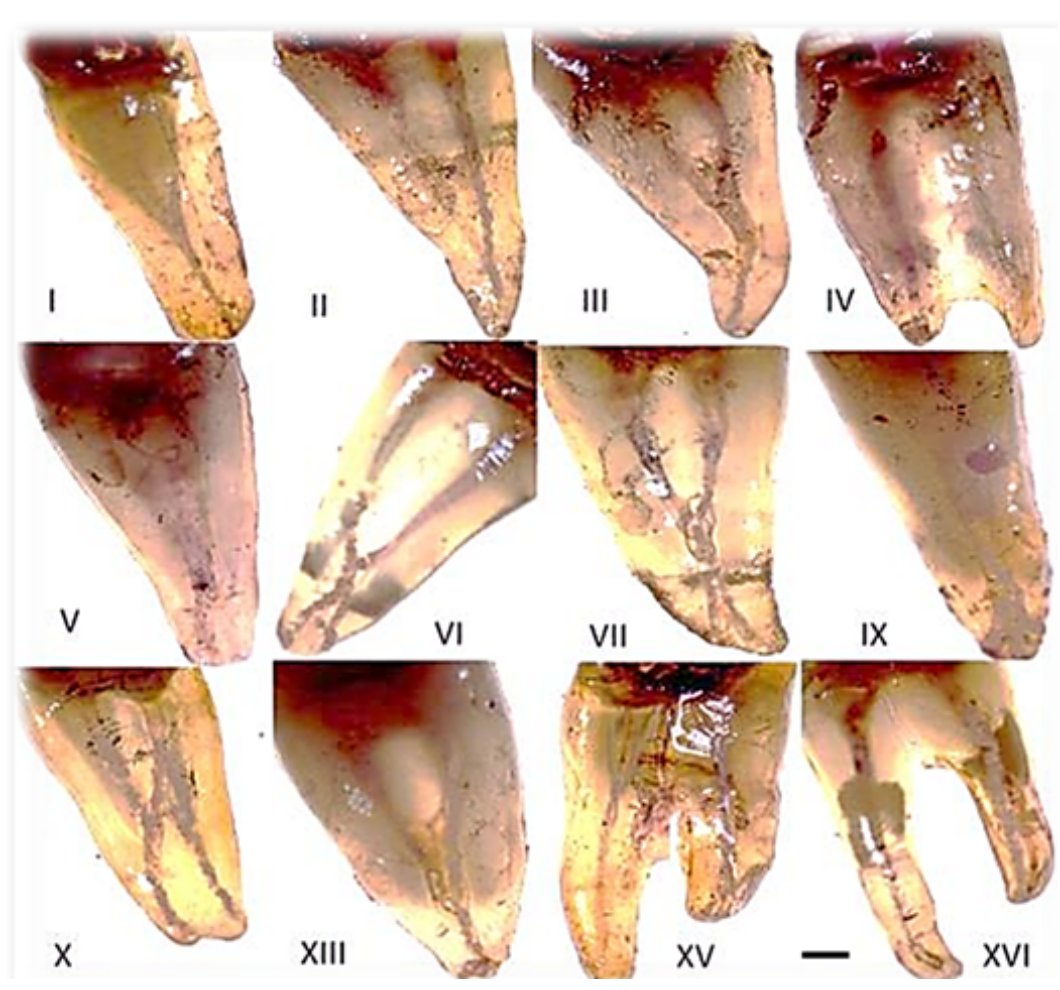

Figure 5: Canal configurations of sample Premolar teeth based on Modified Vertucci and Sert classification

$\begin{array}{llll}\mathrm{I}=(\mathbf{I}, \boldsymbol{I}) \dagger & \mathrm{II}=(\mathbf{2}-\mathbf{I}) & \mathrm{III}=(\mathbf{I}-\mathbf{2}-\mathbf{I}) & \mathrm{IV}=(\mathbf{2}, 2) \\ \mathrm{V}=(\mathbf{I}-2) & \mathrm{VI}=(\mathbf{2}-\mathbf{I}-2) & \mathrm{VII}=(\mathbf{I}-\mathbf{2}-\mathbf{I}-2) & \mathrm{IX}=(\mathbf{I}-3) \\ \mathrm{X}=(\mathbf{I}-\mathbf{2}-\mathbf{3}-2) & \mathrm{XIII}=(\mathbf{I}-\mathbf{2}-\mathbf{I}-3) & \mathrm{XV}=(\mathbf{3}-2) & \mathrm{XVI}=(\mathbf{2}-3), \text { Scale }=2 \mathrm{~mm}\end{array}$

† Notation in all parentheses shows root canal numbers from the crown to the apex (first \& middle digits, bold) and canal exits (last digits, italics)

difference for parameter "mesial surface depression" $(\mathrm{P}<.00 \mathrm{I}$, chisquare test) with $76.2 \%$ first premolars with mesial surface depression. In both groups teeth with various forms of two roots had a significantly higher percentage of this depression as compared to single rooted teeth $(\mathrm{P}<.00 \mathrm{l}$, one way Anova \& post hoc Tukey test).

Further details of canal configuration and presence of canal isthmi and lateral canals were observed under stereomicroscope. Based on modified root canal configuration (Vertucci \& Sert), twelve types of canal configurations were found in sample teeth as illustrated in (Figure 5). In the first premolars, ten types of canal forms were identified of which the greatest percentage were type IV ( 2 canal, 2 exit)
(61.9\%), while in second premolars seven types were identified with type II $(35.2 \%)$ as the predominant morphology $(\mathrm{P}<.00 \mathrm{I}$, Chi- square test, Figure 6).

Furthermore there was a positive correlation between the external root morphology and the canal configurations $(0.196$, Pearson correlation) with significance of $p=0.004$. Thus, in all single and double rooted morphologies Type IV canal configuration was the commonest finding in first premolars. On the other hand in the second premolars Type II along with Type IV was the commonest configuration in all root morphologies. There was no significant difference of canal variations between males and females $(p=0.893$, Fisher's exact) or between pashtun and hindkun groups $(p=0.587$, Fisher's exact). Though for both demographics Type IV was the commonest form in first premolars whereas second premolars had a more variable picture of Type I, II, IV and VI. Our population based on gender and ethnicity does not appear to favour Types VIII, IX, X, XI, XII, XIII, XIV, XV and $X V I$ types.

Approximately, $80 \%$ of the first premolars and $90 \%$ of second premolars had no identifiable lateral canals. Half of the lateral canals were observed in apical third of roots in both first and second premolar.

Position and presence of inter canal communication was observed with no inter canal communications in $\sim 92 \%$ of the premolars. Comparatively high percentage of inter canal isthmi was found in second premolar as compared to first premolar in middle and apical thirds of the root $(P<.05$, Chi- Square test),

\section{DISCUSSION}

Ethnic differences in teeth root anatomy have long been recognized, but the frequency of these variations in root form and canal anatomy has not been documented. ${ }^{14}$ This study aimed to identify the gross anatomical and microscopic anatomic variability of root and canal configuration of maxillary premolars in our population in general and to compare the anatomical difference of maxillary first premolars to maxillary second premolars. Various methods are used to identify these variations whereas our main emphasis was on the clearing technique, as it is as effective as other expensive radiographic methods like $\mathrm{CBCT}$ in vitro. $^{15,16}$

In our study there was equal distribution of premolars in both genders but with majority belonging to the Pashtun linguistic group. Based on modified root form classification we identified ten types of canal forms in our population with Type IV being the predominant morphology in first premolars and Type II in the second premolars. We also identified five main root forms; single root, two separate roots, laminated root free at apexl/3, laminated root free at middlel $/ 3$ and full fused bifid 


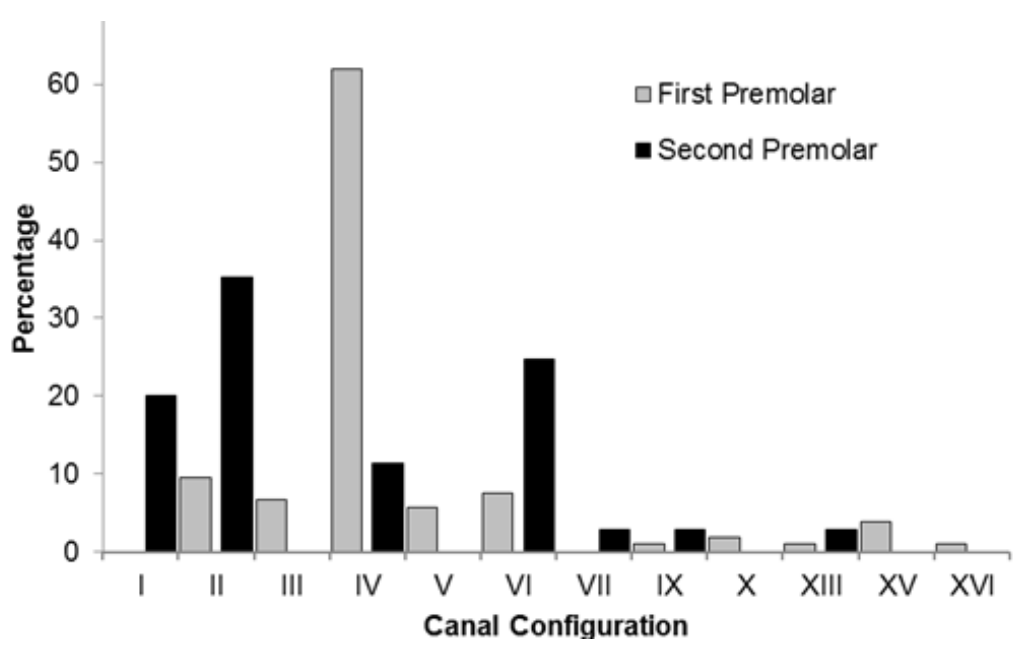

Figure 6: Modified Vertucci \& Sert canal configuration of Premolars, $(\mathrm{P}<0.00 \mathrm{I}$, chi-square $)$

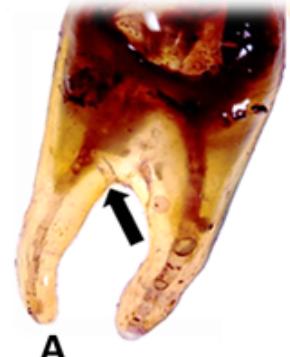

A

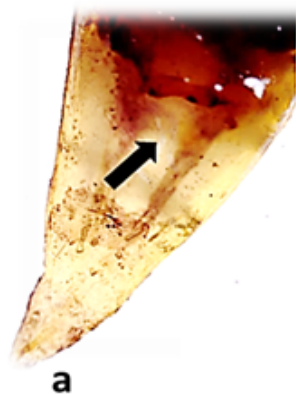

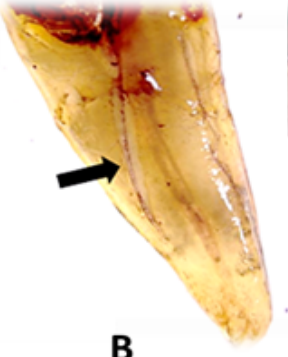

B

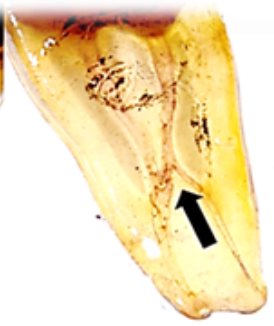

b

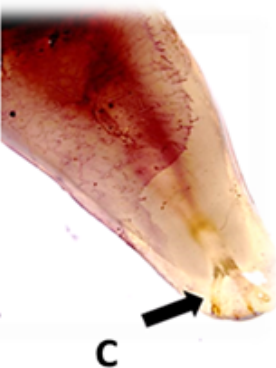

C

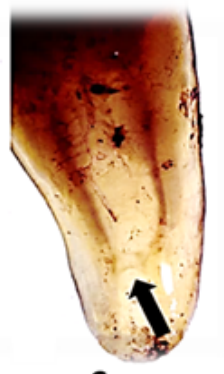

C

Figure 7: Stereoscopic images of Premolars illustrating lateral canals (A, B \& C) and inter canal communications ( $\mathrm{a}, \mathrm{b}$ \& $\mathrm{c}$ )
A, a: Cervical I/3
B, b: Middle I/3
C,c: Apical $\mathrm{I} / 3$ Scale $=2 \mathrm{~mm}$

roots in our population. However, there was no significant difference based on gender or linguistic ethnicity. In addition we also observed other identifiable parameters such as relative root length, lateral canal exits, mesial depression, inter-canal communication and external root formations. The second premolars had a significantly greater frequency of lateral canal exits as compared to first premolars; on the contrary significantly greater percentage of the first premolars had mesial surface depressions.

Tooth lengths in different ethnic groups of the world e.g. Denmark, ${ }^{17}$ Sweden, ${ }^{18}$ U.S.A and Turkey ${ }^{19}$ have shown no significant differences between first and second premolars ${ }^{17}$ as shown in our study. However Kim et al. in his study showed that Asians had shorter tooth length than Caucasians in a study conducted in Korea. ${ }^{20}$ Though in our study the absolute root lengths in both premolar groups were more or less similar but as demonstrated in studies by Pecora, ${ }^{21}$ Black, ${ }^{22}$ and Anderson ${ }^{17}$ the buccal root length was relatively longer in the second premolars. Similarly Tsukiyama et al., working on Asian and White Caucasian populations identified a similar trend. ${ }^{23}$ The understanding of possible variations in the root lengths is very important for a dentist to aid him/her in devising a more precise treatment plan for the patients. These lengths are calculated on in vitro samples whereas a dentist works on in vivo teeth with most of the root embedded into the gum. Therefore in addition we postulated a relative root length as a better indicator for dentists to estimate the root length by observation of visible crown which would be in the ratio of $1: 3$ (crown: root) in double roots and $1: 2$ in single root teeth.

Historically studies have documented root forms as single or double root form but we further elaborated sub varieties of the two rooted teeth forms depending on extent of lamination., ${ }^{2,24}$ The need for this further subclassification arose because of a lack of uniformity in accepted guidelines on assigning root forms. ${ }^{25}$ Especially in bifurcated teeth with free apical third; as the question was whether to classify them as single rooted or double rooted. Such teeth were considered double rooted in studies conducted by Walker, ${ }^{25}$ Awawdeh, ${ }^{8}$ Nelson and Pineda. ${ }^{26}$ We followed the same criteria and placed such teeth in the double rooted category; labeled as laminated but separate at apical third. Though there was an overall preponderance of single root teeth; almost all sub types of double rooted teeth were also identifiable in our population similar to the results by Vertucci, ${ }^{27}$ Kertal, et al., ${ }^{28}$ AJ Chaparro, et al., ${ }^{29}$ Atieh, et al. ${ }^{30}$ and Awawdeh, et al. ${ }^{8}$ The first premolars of Chinese and Mongoloid origin are mostly single rooted contrary to our findings of the second premolar with this feature. ${ }^{25}$ Muana, et al. in Jordanian 
population, ${ }^{31}$ Pecora et al. in Brazilian population $^{2}$ and Trope, et al. in Negroid patients ${ }^{32}$ also found that single rooted teeth were comparatively more in second premolars than double rooted teeth. Though we could not identify a significant difference in the two premolar groups based on the linguistic ethnicity (pashtun versus hindkun) in this study. The variations reported by these studies in various ethnic groups may indicate a potential clue to identification of premolars in the larger context of races: Caucasian, Asian, South American etc. Similar to a study conducted on a Spanish population ${ }^{33}$ we could not identify any significant dimorphism in the premolar teeth.

Looking into further detail on the internal canal configurations the variability in results; as reported by various studies becomes even more complicated. Our study reports Type IV and Type II as the commonest forms in first and second premolars, respectively as reported by Al-Ghananeem et al. ${ }^{31}$ and some studies on Turkish ${ }^{19}$ and Jordanian populations. ${ }^{8}$ On the other hand Type III was the commonest reported form by another study on Turkish population ${ }^{14}$ as well as one on Saudi population. ${ }^{30}$ Thus even within countries there appear to be regional differences. We may surmise that as Turkey, Jordan and Saudi Arabia are in same continent "Asia" so their populations show nearly same pattern of canal configuration i.e. Type II, III and IV. These differences may to some extent be explained by the various techniques used; a 2D image from a radiograph would have its own limitations including quality of the resolution and missing information, on the other hand a 3D image of the actual canal by clearing and dye injection produces clearer visualization of the canals in all dimensions. ${ }^{6}$ It well worthwhile to compare these techniques especially with the advent of cone-beam computed tomography techniques for in-vivo use. ${ }^{34}$

The majority of premolars in our study had two canals as the commonest configurations are; Types II, IV and VI as also shown by Bellizzi, et al., ${ }^{35}$ Caliskan, et al. ${ }^{19}$ However a Brazilian study and
Vertucci as well identified Types I and III with a one canal configuration. ${ }^{2 !}$ Thus it is imperative for the endodontist to understand this morphological character which is irrespective of an external root form because missing an extra canal may lead to treatment failure. Further complicating matters for the dentist who works mainly blindly to occlude or treat all canals and their communications is the presence of lateral canals and inter-canal communications (isthmi) along the length of the root. Mostly both of these were found at apical third of the root in our study and also by Kertal, et al. ${ }^{28}$ However, Vertucci found more lateral canals at middle third of the roots while canal isthmi were more at apical third of the roots in both first and second premolars. $^{1,27}$

Our study showed that there was a mesial surface depression, starting approximately, at the cemento-enamel junction to middle of the root with more than two thirds of the first premolars with this distinguishing feature as compared to the second premolars as did Marlin, et al. (USA) $)^{36}$ and Pecora, et al. (Brazil). ${ }^{2 !}$ Thus dentists should take particular care while placing posts in such teeth to avoid perforation in such roots.

Vertucci found more lateral exits and less central exits in first premolars ${ }^{27}$ as well as in second premolar.' This finding is opposite to our finding where both first and second premolar teeth with one root form had apical root canal exit while two root forms showed apical as well as lateral exit. One reason maybe aging or excessive occlusal forces on the teeth which leads to thickening of apical cementum resulting into displacement of apical foramen further from center. ${ }^{37}$ This aspect maybe further explored as Vertucci did not identify any demographics in his study.'

\section{CONCLUSION}

We identified a range of variations in the canal configurations in first and second premolars. The first premolars have mostly two roots with a type IV canal configuration (2 canals and 2 exits), while second premolars have single roots on external morphology but with a greater variation internally of: type I, II, IV and type VI canal form. Thus, second premolars have a much more diverse configuration ranging with mostly two canals and a variety of exits. Thus for a successful endodontic procedure a sound anatomical knowledge of the canals would lead to better treatment and less chances of failure.

Though we could not identify any gender of linguistically identifiable features in our population this study adds to the larger body of international studies conducted on various populations the world over and may form the basis for further forensic identification studies.

\section{ACKNOWLEDGEMENT}

We are thankful to Khyber Medical University for partial funding of this project to AS. We would also like to acknowledge technical services of $\mathrm{Mr}$ Jameel, Dental technician DHQ, Kohat and Dr Nadia Aaman Associate Professor Fauji Foundation for her expert opinion.

\section{REFERENCES}

I. Vertucci F, Seelig A, Gillis R. Root canal morphology of the human maxillary second premolar. Oral Surg Oral Med Oral Pathol 1 974;38(3):456-64. DOI: 10.1016/0030-4220 (74)90374-0.

2. Pécora JD, Sousa Neto MD, Saquy PC, Woelfel JB. In vitro study of root canal anatomy of maxillary. Braz Dent J 1993;3(2):8I-5.

3. Cheung L, Lam J. Apicectomy of posterior teeth-a clinical study. Australian Dent 1993;38(I):7-21. DOI: $10.1111 /$ j.1834-7819.1993.tb 05446.x.

4. Levander E, Malmgren O. Evaluation of the risk of root resorption during orthodontic treatment: A study of upper incisors. Eur J Orthod 1988; I0(I):30-8. DOI: 10.1093/ejo/ 10.1.30.

5. Cleghorn BM, Christie WH, Dong CCS. The root and root canal morphology of the human mandibular first premolar: A 
Literature Review. J Endod 2007; 33(3):509-16. DOI: 10.1016/j.joen. 2006.12.004

6. Sert S, Bayirli GS. Evaluation of the root canal configurations of the mandibular and maxillary permanent teeth by gender in the Turkish population. J Endod 2004;30(6):39I-8. DOI: 10.1097/ 00004770-200406000-00004.

7. Vertucci FJ. Root canal morphology and its relationship to endodontic procedures. Endod Topics 2005; I0(I):3-29. DOI: 10.1III/j. |60|-|546.2005.00|29.x.

8. Awawdeh LA, Al-Qudah AA. Root form and canal morphology of mandibular premolars in a Jordanian population. Int Endod J 2008; 4 I (3):240-8. DOI: $10.1 \mid$ I I/j. I365259I.2007.0I348.x.

9. Neelakantan P, Subbarao C, Ahuja R, Subbarao CV. Root and canal morphology of Indian maxillary premolars by a modified root canal staining technique. Odontology 20II;99(I):I8-2I. DOI: I0.1007/s 10266-010-0137-0.

10. Stojicic S, Zivkovic S, Qian W, Zhang H, Haapasalo M. Tissue Dissolution by Sodium Hypochlorite: Effect of Concentration, Temperature, Agitation, and Surfactant. J Endod 2010;36(9): I558-62. DOI: 10.1016/ j.joen.2010.06.02I .

II. Evans M, Davies JK, Sundqvist G, Figdor D. Mechanisms involved in the resistance of Enterococcus faecalis to calcium hydroxide. Int Endod J 2002;35(3):22I-8. DOI: I 0.1046/j. I 365-259|.2002. 00504.x.

12. Rehman K, Khan F, Habib S. Diaphonization: A Recipe to Study Teeth. J contemp Dent Pract $20|5 ;| 6(3): 248$ - 5I. DOI: 10.5005/jp-journals-10024-1670.

13. Vertucci FJ. Root canal anatomy of the human permanent teeth. Oral Surg Oral Med Oral Pathol 1984;58(5):589-99. DOI: 10.1016/ 0030-4220(84)90085-9.

14. Özcan E, Çolak H, Hamidi MM. Root and canal morphology of maxillary first premolars in a Turkish population. J Dent Sci 2012;7(4): 390-394. DOI: I0.1016/j.jds.20I2. 09.003 .

15. Neelakantan P, Subbarao C, Subbarao CV. Comparative evaluation of modified canal staining and clearing technique, cone-beam computed tomography, peripheral quantitative computed tomography, spiral computed tomography, and plain and contrast mediumenhanced digital radiography in studying root canal morphology. J Endod 20I0;36(9):|547-5I. DOI: 10.1016/j.joen.2010.05.008.

16. Robertson D, Leeb IJ, Mckee M, Brewer E. A clearing technique for the study of root canal systems. Endod 1980;6(I):42 I-4. DOI: I0.1016/S0099-2399(80)802I8-4.

17. Andreasen J, Paulsen H, Yu, Bayer T. A long-term study of 370 autotransplanted premolars. Part IV. Root development subsequent to transplantation. Eur J Orthod 1990; I2(I):38-50. DOI: 10.1093/ ejo/I 2.I.38.

18. Thanyakarn C, Hansen K, Rohlin M, Akesson L. Measurements of tooth length in panoramic radiographs. I. The use of indicators. Dentomaxillofac Radiol 1992;2 I ( ): 26-30. DOI: I0.I259/dmfr.2I.I. 1397447.

19. Çalişkan MK, Pehlivan Y, Sepetçioğlu $F$, Türkün $M$, Tuncer SŞ. Root canal morphology of human permanent teeth in a Turkish population. J Endod 1995;2I (4):200-4. DOI: I0. 1016/S0099-2399(06)80566-2

20. Kim E, Fallahrastegar A, Hur Y-Y, Jung I-Y, Kim S, Lee S-J. Difference in root canal length between Asians and Caucasians. Int Endod J 2005;38(3):|49-5|. DOI: 10. I I II/j.I365-259I.2004.0088I.x.

21. Pecora JD, Saquy P, Sousa Neto M, Woelfel J. Root form and canal anatomy of maxillary first premolars. Braz Dent J 1991;2(2):87-94.

22. Black GV. Descriptive anatomy of the human teeth. $2^{\text {nd }}$ edition. 1892. Wilmington Dental Manufacturing

\section{Co. Philadelphia}

23. Tsukiyama T, Marcushamer E, Griffin TJ, Arguello E, Magne P, Gallucci GO. Comparison of the anatomic crown width/length ratios of unworn and worn maxillary teeth in Asian and white subjects. J Prosth Dent 2012;107(1):1-16. DOI: 10.1016/S0022-39|3(I2)60009-2.

24. Gupta S, Sinha DJ, Gowhar O, Tyagi SP, Singh NN, Gupta S. Root and canal morphology of maxillary first premolar teeth in north Indian population using clearing technique: an in vitro study. J Conserv Dent 20I5; 18(3):232-6. DOI: 10.4103/ 0972-0707.157260.

25. Walker RT. Root form and canal anatomy of maxillary first premolars in a southern Chinese population. Endod Dent Traumatol 1987;3(3):|30-4. DOI: $10.1111 /$ j. |600-9657.|987.tb006|4.x.

26. Pineda F, Kuttler Y. Mesiodistal and buccolingual roentgenographic investigation of 7,275 root canals. Oral Surg Oral Med Oral Pathol | $972 ; 33(\mathrm{I})$ : | 0 I - | 0. DOI: 10.1016/0030-4220(72)902।4-9.

27. Vertucci FJ, Gegauff A. Root canal morphology of the maxillary first premolar. J Am Dent Assoc 1979;99(2):194-8. DOI: 10.14219/ jada.archive. 1979.0255 .

28. Kartal N, Özçelik B, Cimilli H. Root canal morphology of maxillary premolars. JEndod 1998;24(6):4I 7 9. DOI: 10.1016/50099-2399(98) 80024-I.

29. Chaparro AJ, Segura JJ, Guerrero E, Jiménez-Rubio A, Murillo C, Feito JJ. Number of roots and canals in maxillary first premolars: study of an Andalusian population. Endod Dent Traumatol 1999;15:65-7. DOI: | $0.1|\mathrm{I}| / \mathrm{j} .1600-9657$. 1999.tb00755.x.

30. Atieh MA. Root and canal morphology of maxillary first premolars in a Saudi population. J Contemp Dent Pract 2008;9(I):4653

31. Al-Ghananeem MM, Haddadin K, Al-Khreisat AS, Al-Weshah M, Al- 
Habahbeh N. The number of roots and canals in the maxillary second premolars in a group of jordanian population. Int J Dent 2014;2014: 797692. DOI: $10.1155 / 2014 /$ 797692.

32. Trope M, Elfenbein L, Tronstad L. Mandibular premolars with more than one root canal in different race groups. J Endod 1986; 12(8):343-5. DOI: $10.1016 / 50099-2399(86)$ 80035-8.

33. Abella F, Teixidó LM, Patel S, Sosa F, Duran-Sindreu F, Roig M. Conebeam computed tomography analysis of the root canal morphology of maxillary first and second premolars in a Spanish population. J Endod 20I5;4I(8): I24I-7. DOI: I0.1016/j.joen.2015. 03.026 .

34. Zhang R, Wang H, Tian Y-Y, Yu X, Hu $T$, Dummer PMH. Use of cone-beam computed tomography to evaluate root and canal morphology of mandibular molars in Chinese individuals. Int Endod] 20II;44(II):990-9. DOI: I0.1। II/j.|365-259।.20। I. 01904.x.

35. Bellizzi R, Hartwell G. Radiographic evaluation of root canal anatomy of in vivo endodontically treated maxillary premolars. J Endod 1985; I I(I):37-9. DOI: 10.1016/ S0099-2399(85)80I04-7.

36. Gher ME, Vernino AR. Root morphology-clinical significance in pathogenesis and treatment of periodontal disease. J Am Dent Assoc 1980;101(4):627-33. DOI: 10.142 19/jada.archive. 1980.0372 .

37. Kuttler Y. Microscopic investigation of root apexes. J Am Dent Assoc 1955;50(5):544-52. DOI: I 0. |4219/jada.archive. 1955.0099 .

\section{AUTHORS' CONTRIBUTIONS}

Following authors have made substantial contributions to the manuscript as under:

AS \& ZH: Conception and study design, drafting the manuscript, final approval of the version to be published

S]: Analysis and interpretation of data, critical review, final approval of the version to be published

AM: Acquisition, analysis and interpretation of data, drafting the manuscript, final approval of the version to be published

Authors agree to be accountable for all aspects of the work in ensuring that questions related to the accuracy or integrity of any part of the work are appropriately investigated and resolved.

CONFLICT OF INTEREST

Authors declared no conflict of interest

GRANT SUPPORT AND FINANCIAL DISCLOSURE

The study was partially supported by research grant to first author from Office of Research, Innovation and Commercialization (ORIC), Khyber Medical University, Peshawar, Pakistan

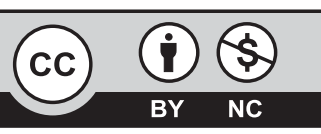

This is an Open Access article distributed under the terms of the Creative Commons Attribution-Non Commercial 2.0 Generic License.
KMUJ web address: www.kmuj.kmu.edu.pk

Email address: kmuj@kmu.edu.pk 